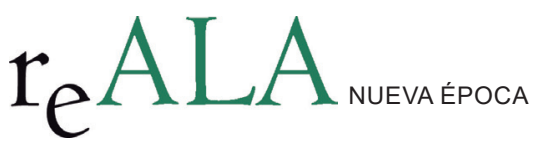

REALA, Nueva Época - N. ${ }^{\circ}$, enero-junio 2016 - ISSN: 1989-8975

DOI: http://dx.doi.org/10.24965/reala.voi5.10349

\author{
Francisco Jesús Ferreiro Seoane \\ University of Santiago of Compostela \\ franciscojesus.ferreiro@usc.es
}

\title{
La RPT como un instrumento de organización de las administraciones locales
}

\section{Resumen}

Este artículo pretende aportar una metodología académica que sirva para la elaboración de una Relación de Puestos de Trabajo (RPT) en las administraciones locales, basada en criterios objetivos y cuantificables que permita la valoración técnica y económica de cada puesto de trabajo.

Para ello se ha revisado la literatura y el marco conceptual, analizando las diversas aportaciones de autores y académicos, explicando qué es un RPT, cuáles son los objetivos, sus ventajas e inconvenientes, dificultades y los trámites para su aprobación y posterior modificación.

Finalmente con la metodología propuesta, se analiza el caso real de una implantación de la RPT en una administración local en España, sus logros y sus limitaciones.

Palabras clave

Relación de Puestos de Trabajo (RPT), Administración Local, Recursos Humanos, Modelos Organizativos, Manuel de Funciones.

\section{The List of Job Positions (RPT) as an instrument of organization of local administrations}

Abstract

This article tries to explain an academic methodology useful for the development of a List of Job Positions (RPT in Spanish) in local administrations, based on objective and quantifiable criteria that allow the technical and economic valuation of each job position.

To do that, literature and conceptual framework has been revised analyzing the different contributions of authors and academics explaining what a RPT is, which are its objectives, its advantages and disadvantages, its difficulties and the procedure for its approval and subsequent modification.

Finally, with the methodology proposed, the real case of an implementation of the RPT in a local administration in Spain is analyzed, together with its achievements and limitations.

Keywords

List of Job Positions (RPT), Local Administration, Human Resources, Organizational Models, Functions Manual. 


\section{INTRODUCCIÓN}

Los continuos cambios y trasformaciones a los que se enfrentan las organizaciones actuales, han obligado a éstas a adecuar las estructuras anticuadas y rígidas en sistemas avanzados y flexibles. Toda organización, aunque haya sido perfectamente diseñada, con el paso del tiempo sufre una redistribución de sus funciones, de ahí que cada cierto tiempo sea necesario un análisis funcional'1.

Esto ha supuesto establecer sistemas y procesos adaptativos para las nuevas estructuras, que precisaban de técnicas que les permitiesen afrontar las nuevas problemáticas a las que se enfrentan las Organizaciones, lo que ha conllevado a elevar la flexibilidad en el campo de los recursos humanos. Tanto desde el punto de vista del derecho administrativo ${ }^{2}$ como desde el politológico ${ }^{3}$ los defectos del sistema de personal local han sido claramente visibles: «predominio del localismo; centralización del sistema; alta politización; clientelismo latente; baja profesionalización» 4 .

Al igual que el resto de las organizaciones, las entidades públicas locales, deben fijar sus objetivos, y dotarse de un diseño y estructura adecuados. Para ello, el trabajo en las organizaciones debe ordenarse de igual forma para lograr la eficiencia.

Por tanto, hay que delimitar el número de puestos de trabajo necesarios y los requisitos que deben cumplir las personas que los desempeñen, atendiendo a dos objetivos: las actividades y tareas que han de desempeñarse, y los límites presupuestarios. Así, como adecuar las cifras de personal a dichas necesidades, incrementando o reduciendo plantilla; y dotar a esta plantilla de recursos para la realización de sus tareas. Siendo imprescindible la labor de describir, clasificar y valorar los puestos de trabajo. Es decir, la realización de la Relación de Puestos de Trabajo (RPT).

Para la ordenación del trabajo en las Entidades públicas locales podemos utilizar instrumentos objetivos o subjetivos. La RPT es un instrumento objetivo de ordenación, ya que la valoración de dicho trabajo se hace desde el análisis del puesto de trabajo, «éste es el elemento protagonista y básico»5, «separar al empleado de la función» ${ }^{6}$. Cuando se usan instrumentos subjetivos, el trabajo se ordena mediante la constitución de grupos (cuerpos y escalas), asignando trabajos concretos a cada grupo según su importancia, y valorando la calidad del trabajo realizado y la productividad de cada persona.

Estos dos instrumentos se encuentran frecuentemente mezclados, se produce una realidad mixta, y este es el caso de las administraciones españolas?.

Nosotros lo que hemos hecho es una ordenación del trabajo de carácter objetivo, basándonos en los puestos de trabajo, lo que se denomina Relación de Puestos de Trabajo.

La relaciones de puestos de trabajo, cuya regulación se contenía inicialmente en los artículos 15 y 16 de la ley 30/1984 (LMRFP) ${ }^{8}$ aún vigentes, y hoy se establece en el artículo 74 del EBEP9, constituyen la gran alternativa al sistema de Cuerpos, en cuanto pieza fundamental de una concepción distinta de la organización del empleo público. La relación de puestos de trabajo parte de la definición de las funciones de cada puesto, de la determinación del número de titulares que deben desempeñar cada uno a fin de prestar los servicios necesarios. La definición de las funciones, y demás características del puesto (horario, dedicación, posición jerárquica, forma de provisión, requisitos para su desempeño, penosidad, peligrosidad, etc.), aportan los elementos necesarios para proceder a la valoración de los mismos, determinándose así el importe del com-

1 SÁNCHEZ Motos, Enrique (1996): Análisis del funcionamiento de las organizaciones. Mimeo.

2 Opinión mantenida por SÁNCHEZ MoRón, Miguel (1998): “Balance de la Función Pública”. En La posición institucional de la Aministración Local ante el Siglo XXI. IVAP. Oñati; LLISET BORRELL, Francisco y GRAU ÁvILA, Sebastián (1992): “La Función Pública Local.” En Informe sobre el Gobierno Local. Madrid. MAP y Fundación Pi y Sunyer; CASTILLO BLANCO, Federico (1998), coordinador: Situación actual y tendencias de la función pública española. Comares-CEMCI. Granada.

3 Opinión mantenida por BAÑón MARTÏNEZ, Rafael (1986): “Función Pública Local en España: Movilidad, carrera y profesionalización del personal.” CIVITAS. Revista Española de Derecho Fiscales. Ad; CARRILlo BARRoso, Ernesto (1991): Gestión de Recursos Humanos, presupuestación y hacienda local en España. Madrid. Instituto de Estudios Fiscales.

4 CUenCA CerverA, J. Javier (2004): “La Dirección de Recursos Humanos en los Pequeños Ayuntamientos". VI Jornadas Canarias de Administración Local. Santa Cruz de La Palma: 12 de mayo de 2004.

5 CORRAL VILLALBA, Juan (2001): Cómo hacer la valoración de puestos de trabajo en un Ayuntamiento: La Relación de Puestos de Trabajo, Civitas.

6 GARCÍA DE ENTERRÍA, Eduardo: “La organización y sus agentes: revisión de estructuras.” En La Administración española: estudios de ciencia administrativa. Civitas. Madrid.(e.o. 1961).

7 CORRAL VILLALBA, Juan (2001)

8 Ley 30/1984, de 2 de agosto, Medidas para la Reforma de la Función Pública.

9 Real Decreto Legislativo 5/2015, de 30 de Octubre, por el que se aprueba el texto refundido de la Ley del Estatuto Básico del Empleado Público.

REALA, Nueva Época, - N. ${ }^{5}$, enero-junio 2016 - ISSN: 1989-8975 - DOI: 10.24965/reala.voi5.10349 
plemento específico que ha de asignarse a cada uno. La obligatoriedad de las RPT fue impuesta por la Ley $30 / 1984^{10}$, «si bien su aplicabilidad directa en la Administración Local ha quedado un tanto confusa y es todavía objeto de debate» ${ }^{11}$.

La situación actual del desarrollo de la Relación de Puestos de Trabajo como instrumento de gestión es ignorada por un importante número de Corporaciones Locales, y mucho más cuanto menor es su tamaño. Son los ayuntamientos de cierto tamaño y las diputaciones quienes con mayor o menor fortuna han abordado estos documentos $^{12}$. Por lo tanto no están definidas las líneas maestras de la Política de Personal, el saber hacia dónde vamos, en los términos empleados por autores como Ramió y Ballart ${ }^{13}$.

\section{OBJETIVOS}

El objetivo del presente trabajo, una vez revisada toda la teoría existente y su marco conceptual sobre la Relación de Puestos de Trabajo, es exponer un método de elaboración de RPT contrastado empíricamente. La relación de puestos de trabajo es la tendencia organizativa en los órganos locales, y sin embargo ha sido muy poco explorada, nos encontramos ante una gran carestía de información desde el punto de vista teórico. La mayor parte de artículos sobre la materia se centran en la problemática de su naturaleza jurídica, y no en la explicación de modelos metodológicos que contribuyan a solventar las dudas que surgen a nivel técnico a la hora de realizar e implementar una RPT. Es necesario un buen marco teórico y metodológico que explique cómo debe elaborarse, y contemple los problemas que pueden llegar a surgir. Por ello, el presente artículo tiene como objetivo contribuir a la creación de este marco teórico-práctico tan necesario, y la exposición de un modelo práctico que ha servido de base para la negociación de una RPT en un ayuntamiento en España.

\section{CONCEPTO Y CONTENIDO DE LA RPT}

El artículo 15 de la LMRFP ${ }^{14}$, define la RPT como «Instrumento técnico a través del cual se realiza la ordenación del personal, de acuerdo con las necesidades de los servicios y se precisan los requisitos para el desempeño de cada puesto, así como sus características retributivas». Así pues, «las relaciones se caracterizan por reunir en un único texto o documento los rasgos más distintivos de cada uno de los puestos existentes, que pasan a quedar ordenados y ordenar las sucesivas provisiones por los funcionarios adecuados a los mismos» ${ }^{15}$.

La naturaleza jurídica de las RPT ha sido una cuestión controvertida. «Algún sector doctrinal se ha pronunciado expresamente sobre esto, oscilando entre los que consideran que son verdaderas normas jurídicas ${ }^{16}$ y los que creen que no podemos hablar sino de simples actos administrativos con destinatario general» ${ }^{17}$. Existe una regulación fragmentada y muy heterogénea sobre este tema, por lo que durante años se asumió su naturaleza híbrida o mixta ${ }^{18}$ por parte del Tribunal Supremo, para poder posibilitar el acceso a casación, lo que le valió la consideración de disposición de carácter general a efectos procesales. Tras la sentencia de 5 de febrero de 2014 (EDJ 2014/31816) dictada por el Contencioso-Administrativo del Tribunal Supremo, el Alto Tribunal ha determinado, para futuro, la naturaleza jurídica de la RPT como acto-condición administrativo, ordenado y no ordenador de los efectivos públicos, abandonando la anterior doctrina jurisprudencial de acto de naturaleza híbrida. Esta

10 Ley 30/1984, de 2 de agosto, Medidas para la Reforma de la Función Pública.

11 Bocinós RoIBoó, M. Inés (2006): “Instrumentos de Ordenación de Gestión de Recursos Humanos, Especial Referencia a la Administración Local”. Revista Cemci, n. ${ }^{\circ} 6$ enero-marzo.

12 Cruz Herrera, M. ${ }^{a}$ Cristina (2013): “La Relación de Puestos de Trabajo. Una Crítica a la Situación Actual”. Revista Cemci, n. 19 abriljunio 2013.

13 BALLART, Xavier y RAmió, Carles (2000): Ciencia de la Administración. Ed. Tirant lo Blanch. Valencia.

14 Ley 30/1984, de 2 de agosto, Medidas para la Reforma de la Función Pública.

15 ARROYO YANES, Luis Miguel (1994): La carrera administrativa de los funcionarios públicos. Editorial Tirant Lo Blanch. Valencia.

16 Esta posición se ha mantenido por FONDEVILA ANTOLín, Jorge (1990): “Nuevos aspectos sobre la naturaleza de las estructuras orgánicas y relaciones de puestos de trabajo: Jurisprudencia reciente", Revista Vasca de Administración Pública 28; MoREY JuAN, Andrés (2000): "Las relaciones de puestos de trabajo: su naturaleza jurídica y problemática", Revista General del Derecho; CORDERO SAAVEDRA, Luciano (2002) “La controvertida naturaleza jurídica de las relaciones de puestos de trabajo en las administraciones públicas", Actualidad Administrativa 26.

17 Esta posición se mantiene por ALDOMÀ i BUIXADÉ, Josep (1996): Les relacions de llocs de treball de les administracions públiques, Cedecs, Barcelona; Moreu CARBonelL, Elisa (1997): "Las relaciones de puestos de trabajo en el proceso de reforma de las administraciones públicas", Revista de Administración Pública 144; DE VICENTE DOMINGO, Ricardo (1997): El puesto de trabajo en el derecho de la función pública,Tirant Lo Blanch, Valencia; GARCíA DE ENTERRÍA, Eduardo; FERNÁNDEZ, Tomás-Ramón (2002): Curso de Derecho Administrativo I, Madrid.

18 Palomar Olmeda, Alberto (1996): Derecho de la función pública. Dykinson, Madrid, se remite a la STS de 29 de noviembre de 1994 , según la cual las RPT: “[...] pueden considerarse como el filo de la balanza entre ambas calificaciones.

REALA, Nueva Época, - N. 5, enero-junio 2016 - ISSN: 1989-8975 - DOI: 10.24965/reala.voi5.10349 
doctrina supone un cambio importante ya que considerando que «la RPT es el instrumento técnico al servicio de la Administración Pública para la organización efectiva de sus recursos humanos en el uso que pueda hacer de su autonomía y autogobierno, debiendo adaptarla a las necesidades que le exige la prestación efectiva de sus servicios públicos, aquella tiene que responder a necesidades no solo actuales sino reales de la propia Corporación. Este proceso adaptativo exige la posible modificación por la Corporación Local de la RPT cuando no responda a las exigencias que le impone el deber de una prestación eficiente de los servicios públicos, debiendo convertirse en un instrumento dinámico (STS de 5 de febrero de 2014; EDJ 2014/31816) y no estático o pétreo; dinamismo y adaptación que se hallan amparadas por el arco de la garantía constitucional de la autonomía local» ${ }^{19}$

Cada RPT es única y su contenido es diferente según las necesidades de cada organización.

Puede tener muy diferentes alcances, desde mejorar simplemente la productividad, hasta cambiar el conjunto de actividades y objetivos de una organización ${ }^{20}$.

Sin embargo, existe un contenido mínimo exigido por la legislación de carácter básico; el artículo 16 LMRFP21 determina:

«... La Administración Local formará la relación de puestos de trabajo existentes en su organización; que deberán incluir en todo caso la denominación y características esenciales de los puestos; las retribuciones complementarias que les correspondan y los requisitos exigidos para su desempeño.»

Este precepto se complementa con lo regulado en el artículo 90 de la Ley $7 / 1985$, de 2 de abril, de bases del régimen local (LRBRL), donde se señala que las corporaciones locales formarán la relación de puestos de trabajo existentes en su organización, en los términos previstos en la legislación básica sobre la función pública, correspondiendo al Estado establecer las normas con arreglo a las cuales hayan de confeccionarse las relaciones de puestos de trabajo, la descripción de puestos de trabajo-tipo y las condiciones requeridas para su creación. Este mandato coincide con el preceptuado en el artículo 129.2 del Real decreto legislativo 781/1986, de 18 de abril, por el que se aprueba el Texto refundido de las disposiciones legales vigentes en materia de régimen local, que atribuye al Ministerio de Administración Territorial -Ministerio para las Administraciones Públicas- la competencia para establecer las normas con arreglo a las cuales hayan de confeccionarse en las entidades locales las relaciones de puestos de trabajo, la descripción de puestos de trabajo-tipo y las condiciones requeridas para su creación ${ }^{22}$.

También, aunque con carácter no básico, referido exclusivamente a la Administración del Estado, el artículo 15 de LMRFP23 indica el contenido mínimo de las RPT diciendo que:

a) Comprenderán, conjunta o separadamente, los puestos de trabajo del personal funcionario de cada centro gestor, el número y las características de los que puedan ser ocupados por personal eventual, así como los de aquellos otros que puedan desempeñarse por personal laboral.

b) Indicarán, en todo caso, la denominación y características esenciales de los mismos; los requisitos exigidos para su desempeño; el nivel de complemento destino y, en su caso, el complemento específico que corresponda a los mismos, cuando hayan de ser desempeñados por personal funcionario, o la categoría profesional y régimen jurídico aplicable cuando sean desempeñados por personal laboral.

c) Realizarán la creación, modificación, refundición y supresión de puestos de trabajo.

d) La provisión de puestos de trabajo a desempeñar por el personal funcionario, así como la formalización de nuevos contratos de personal laboral fijo, requerirán que los correspondientes puestos figuren detallados en las respectivas relaciones. Este requisito no será preciso cuando se trate de realizar tareas de carácter no permanente mediante contratos de trabajo de duración determinada y con cargo a créditos correspondientes a personal laboral eventual en el capítulo de inversiones.

Se resume en el siguiente cuadro los elementos que deben ser descritos en todo puesto.

19 PeÑA Molina, Marcos (2014): "La nueva doctrina del TS sobre la Relación de Puestos de Trabajo. Aplicación práctica en el ámbito local”. Revista Derecho Local, 1 de julio de 2014.

20 CoRral Villalba, Juan (2000): Manual de Gestión del Personal de la Administración Local, Civitas.

21 Ley 30/1984, de 2 de agosto, Medidas para la Reforma de la Función Pública.

22 MAURI MAJós, Joan (2003): “Las relaciones de Puestos de Trabajo y la Gestión de la Función Pública Local”. Estudios QDL. Fundación Democracia y Gobierno Local.

23 Ley 30/1984, de 2 de agosto, Medidas para la Reforma de la Función Pública.

REALA, Nueva Época, - N. ${ }^{5}$, enero-junio 2016 - ISSN: 1989-8975 - DOI: 10.24965/reala.voi5.10349 


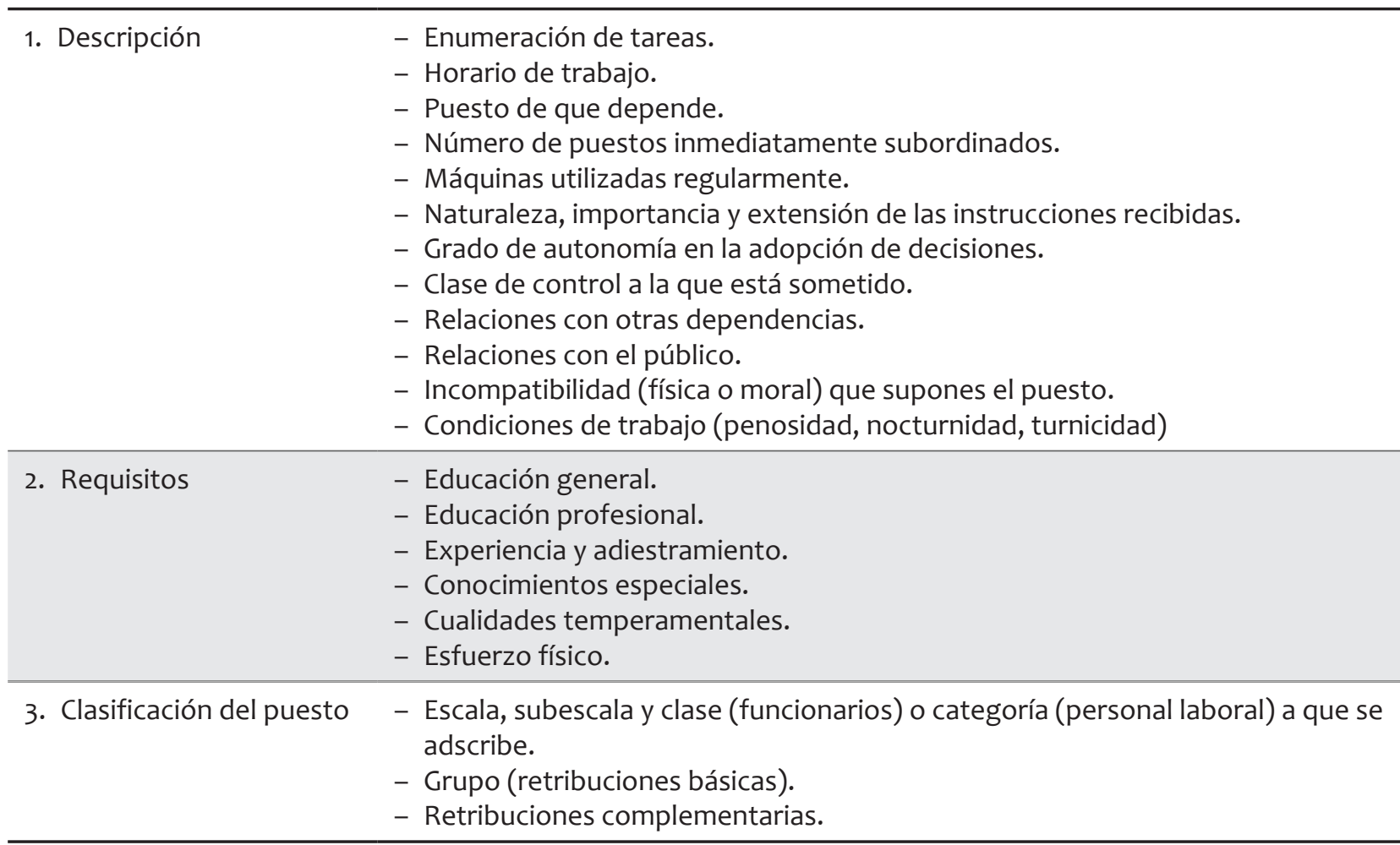

Fuente: CORRAL VILLALBA, Juan (2001)

\section{METODOLOGÍA DE ELABORACIÓN DE UNA RPT}

Metodológicamente la RPT ha de constar de las siguientes fases:

1. La descripción, fase en que se realiza una exposición detallada, estructurada y sistemática de las características inherentes a los puestos.

2. La valoración, evaluación de la importancia de cada puesto en el conjunto y entre sí.

3. El análisis de conjunto, estructurar y ordenar los puestos y tomar decisiones acerca de su adecuación cuantitativa y distributiva a las necesidades y acciones de la organización.

\section{IV.1. Descripción de puestos}

El proceso de elaboración de la RPT comienza con la descripción de los puestos de trabajos que existen en la organización. «La descripción de puestos es el estudio que permite concretar y reflejar documentalmente la naturaleza, contenido y alcance de cada puesto de trabajo en una organización» ${ }^{24}$. En esta etapa de la RPT podemos diferenciar dos fases, una primera en la que se procede a analizar el puesto a través de la recogida de información, y una segunda en la que se procede a describir el puesto en documento apropiado ${ }^{25}$. El proceso de descripción aporta la información que posteriormente será tratada de forma individualizada en la fase de valoración y de forma conjunta en el análisis. La descripción de puestos puede obtenerse a través de varios métodos de recogida de información (observación directa, cuestionarios, entrevistas, etc.).

«No se busca la mayor cantidad de información, sino información útil y concreta» ${ }^{26}$ : Datos sobre la ubicación orgánica de cada puesto en la organización (de quién depende y quiénes dependen de él), importancia, volumen de trabajo, posibilidad de refundición, supresión o necesidad de multiplicación; condiciones de desempeño del puesto (esfuerzo físico, mental, condicionamiento ambiental y horarios); descripción de tareas específicas; y

24 COOPERS Y LYBRAND (1996): "El Capital Humano en la Empresa”. Cuadernos cinco días.

25 Villoria MendietA, Manuel y del Pino MAtute, Eloísa (1997): Manual de Gestión de Recursos Humanos en las Administraciones Públicas, Madrid, TECNOS.

26 CORRAL VILLALBA; Juan (2001).

REALA, Nueva Época, - N. 5, enero-junio 2016 - ISSN: 1989-8975 - DOI: 10.24965/reala.voi5.10349 
requisitos exigidos para su desempeño ${ }^{27}$ (capacidades específicas requeridas, formación y experiencia). «En consecuencia, el análisis de los puestos no es una síntesis de teorías, iniciativas, actitudes o procesos mentales identificados por el analista» ${ }^{28}$, por lo que los rasgos psicológicos del empleado dejan de ser incluidos en el análisis de los puestos, cosa que tradicionalmente se hacía ${ }^{29}$.

«La elección de un método u otro para el análisis de los puestos depende de una serie de preguntas y respuestas como: ¿qué hacer con los resultados?; ¿quién puede recoger la información?; ¿cuándo se necesitan?; ¿qué método será mejor aceptado por los empleados?; ¿cuánto dinero hay?»30.

Se pueden utilizar métodos muy diversos, e incluso combinarlos, se puede optar por la observación, la autodescripción, la entrevista, cuestionarios, etc. Todos ellos tienen sus ventajas e inconvenientes, por lo que no hay un método perfecto y debemos elegir entre uno u otro según nuestras preferencias, características de las entidades y recursos disponibles.

Los mayores inconvenientes que nos podemos encontrar al recoger la información de cada puesto, y que derivan de la técnica o método utilizado son la subjetividad de los datos obtenidos, la complejidad de análisis de los datos y el alto coste tanto de tiempo como monetario. Por lo que es muy importante tener claro qué vamos a hacer, cómo lo vamos a hacer y qué resultado vamos a obtener. Una buena planificación en esta fase es fundamental, pues es la base para el buen resultado de la RPT.

Villoria ${ }^{31}$ hace la siguiente enumeración de los métodos: observación; autodescripción/diarios; entrevista; incidente crítico; comportamiento adecuado; check list; jerarquía de tareas; análisis de trabajo; y cuestionarios. Como ejemplo de una técnica de recogida de información podemos citar a Corral ${ }^{32}$, este autor usa como método básico el cuestionario. El cuestionario tiene la ventaja de implicar al empleado en la actividad descriptiva, ya que el empleado como titular del puesto es quién mejor lo conoce. Pero tiene como desventaja la subjetividad y la injerencia de intereses con la descripción. La recogida de información por medio de este sistema es rápida y económica. La subjetividad puede superarse con un buen diseño del cuestionario. El cuestionario debe combinarse con entrevista del trabajador en su puesto, y con la propia observación del puesto. Una fórmula aún más completa sería completar lo anterior con una entrevista al superior jerárquico.

El análisis de los puestos de trabajo es un proceso objetivo, en la medida en que no tiene en consideración a la persona que ocupa el puesto de trabajo, sino al puesto en sí. Aparece entonces el peligro que acecha a todo analista de puestos: perder la orientación y concentrarse en el titular del puesto de trabajo en lugar de hacerlo en el propio puesto. Esta circunstancia también está presente en el proceso de valoración de los puestos de trabajo.

Los puestos, curiosamente, son considerados como una posesión personal por parte de sus ocupantes, y ello unido al inevitable egocentrismo presente en la interpretación de las percepciones individuales, induce a los empleados a considerar este proceso como una intromisión territorial molesta.

\section{IV.2. Valoración}

Una vez que ya tenemos recogida toda la información, el siguiente paso es valorar los puestos de trabajo, valorar cada puesto de trabajo. La FIET (Federación Internacional de Empleados, técnicos y Profesionales) define la valoración diciendo que «los sistemas de evaluación de las ocupaciones son métodos para medir y evaluar el contenido de las ocupaciones dentro de una organización, con la finalidad de crear una estructura salarial basada en la naturaleza de las ocupaciones y no en los méritos del individuo». «Toda valoración de puestos de trabajo se debe realizar en vacío, sin considerar el ocupante del puesto y, en función de ellos, definir cuánto debería pagarse a dicho puesto" 33 .

Las actividades que se realizan en los puestos de trabajo son no sólo distintas de unos a otros, si no que tienen una mayor o menor importancia. Por lo que debemos asignar a cada uno su valor diferencial, cuantificar esa diferencia de contenidos e importancia entre los puestos, en esto consiste la valoración. La valoración de puestos ha de extenderse a la totalidad de puestos, ya que todos han de obtener una conceptualización que sirva de medida

27 BARRANCO, Francisco Javier (1993): Planificación estratégica de los recursos humanos. Del Marketing interno a la planificación. Madrid. Pirámide.

28 CLIFFord, James P.(1994): “Job Analysis: Why do Do It and How Should It be Done?”. Public Pesonnel Management, vol. 23 , n. 2 1994.

29 FERNÁNDEZ LóPEZ, Ángela Maday (2005): “Análisis y Descripción de los Puestos de Trabajo”. Revista Gestiópolis.

30 Villoria Mendieta, Manuel y del Pino MAtute, Eloísa (1997).

31 VILLORIA MENDIETA, Manuel (1997).

32 CORRAL VILLALBA, Juan (2001).

33 Villoria Mendieta, Manuel y del Pino MAtUTe, Eloísa (1997).

REALA, Nueva Época, - N. ${ }^{5}$, enero-junio 2016 - ISSN: 1989-8975 - DOI: 10.24965/reala.voi5.10349 
para su jerarquización (nivel), para la fijación de sus retribuciones complementarias y para saber cuál es la forma de provisión del puesto. La valoración es el elemento que sirve de motivación y justifica la RPT en la realización de los tres efectos anteriores ${ }^{34}$.

Esta fase no es un mero trámite optativo en la RPT, es un elemento esencial de ésta, pudiendo originarse la nulidad de la RPT si ésta carece de valoración, ya que no existiría motivación para ella. Es importante que en el expediente de elaboración de la RPT quede constancia de que se ha realizado la valoración, pues por el efecto de ésta serán muy habituales las reclamaciones por parte del personal que detenta los puestos, si no están de acuerdo con el nivel y retribución que se le atribuye a cada puesto. Es importante que quede claro en el expediente cuáles fueron los factores que se tuvieron en cuenta para la valoración, que ésta se ha hecho siguiendo unos criterios equitativos, no se ha realizado de manera discrecional.

Existen diversos sistemas de valoración, pero podemos englobarlos todos en torno a dos tipos, los métodos cuantitativos y los no cuantitativos o cualitativos. Corral ${ }^{35}$ nos habla de cinco métodos, los tres primeros son no cuantitativos y serían el sistema de graduación, el sistema de valoración mediante la comparación por pares y el sistema de clasificación de puestos en niveles y categorías. Los métodos cuantitativos son el sistema de constatación de factores y el método de puntuación de factores y grados. Villoria y del Pino ${ }^{36}$ hacen otra clasificación y nos habla de cuatro técnicas de valoración que serían la Jerarquización y la clasificación dentro de los sistemas cualitativos y la comparación de factores y la puntuación de factores como métodos cuantitativos.

La valoración es una operación técnica objetiva, y no es negociable. No obstante, la valoración ha de hacerse eligiendo un sistema de valoración, sobre unos valores y unos criterios, y la elección de todos estos elementos sí debe ser negociada ${ }^{37}$.

\section{IV.3. Trámites}

\section{La RPT como procedimiento}

La RPT es un procedimiento no formalizado o flexible, lo que significa que gran parte de los trámites serán decididos por quién los realiza. Sin embargo, hay también un conjunto de trámites obligatorios que se encuentran unas veces en normas de la legislación general y otras en normas autonómicas; unas veces referidos específicamente a la propia RPT y otras a la tramitación de las disposiciones de carácter general ${ }^{38}$.

«La RPT es un procedimiento de elaboración de disposición normativa con unas especificidades que refuerzan las garantías exigidas en estas disposiciones: Estudios técnicos justificativos de la legalidad y oportunidad de la disposición, audiencia a las instituciones representativas del personal a través de la consulta y de la negociación, así como su publicidad»39.

La RPT podrá ser elaborada tanto por personal interno de la Entidad Local como por personal externo, debidamente contratado, en este caso, deberá tramitarse el correspondiente contrato de servicios, de conformidad con la Ley de Contratos del Sector Público.

A la vista del documento final presentado, por la Alcaldía o Presidencia de la Entidad local, previos los informes que considere oportunos, procederá a su tramitación.

La fase de negociación es un trámite obligatorio, así aparece recogido en el artículo 37.2 a) de la Ley 7/2007, de 12 de abril, del Estatuto Básico del Empleado Público que dispone:

a) Las decisiones de las Administraciones Públicas que afecten a sus potestades de organización.

Cuando las consecuencias de las decisiones de las Administraciones Públicas que afecten a sus potestades de organización tengan repercusión sobre condiciones de trabajo de los funcionarios públicos contempladas en el apartado anterior, procederá la negociación de dichas condiciones con las Organizaciones Sindicales a que se refiere este Estatuto.

Por otro lado la Sentencia de 2 de diciembre de 2010 (rec.4775/2009) de la Sala de lo Contencioso Administrativo del Tribunal Supremo reafirma la obligación actual de negociar las RPT del personal funcionario en las Mesas

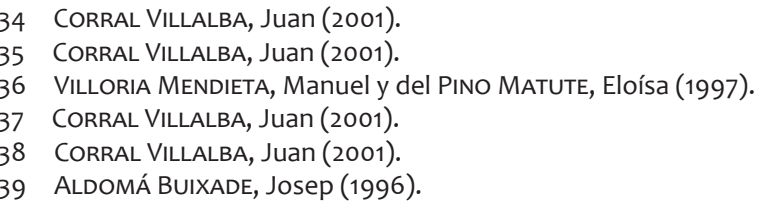

REALA, Nueva Época, - N. 5, enero-junio 2016 - ISSN: 1989-8975 - DOI: 10.24965/reala.voi5.10349 
de Negociación. Además anuda la falta de negociación a la nulidad de pleno derecho de la RPT por afectar al derecho fundamental de la negociación colectiva.

La Comisión negociadora según la legislación en materia de representación y participación del personal materializada en la Ley 21/2006, de 20 de junio, por la que se modifica la Ley 9/1987, de 12 de junio de Órganos de Representación (LOR), establece que, para el personal funcionario existe una mesa general de negociación en cada entidad local como órgano específico de negociación (art. 31). En esta mesa estarán presentes los sindicatos que hayan obtenido el 10 por 100 o más de los representantes en las elecciones para delegados y Juntas de personal (art. 31.2).

Por lo que se refiere al personal laboral, la comisión negociadora prevista en el artículo 88 del Estatuto de los Trabajadores, además del comité de empresa o los delegados de personal (en entidades pequeñas), son los órganos legitimados para la negociación.

A estos órganos se atribuye genéricamente cualquier tipo de negociación y, por tanto, también la de la RPT en las materias comprendidas en el artículo 32 de la LOR y la consulta comprendida en el artículo 34.

Por lo tanto, la comisión negociadora estará formada por los órganos anteriores, el alcalde y los asesores que hayan realizado la RPT. En esta fase se expondrá la RPT y se procederá a la negociación de la RPT. Aunque hay que aclarar que según el Tribunal Supremo, «la negociación no es lo mismo que la concertación -llegar a un acuerdo-, por lo que el bloqueo negociador no impide que la Administración apruebe la RPT».

\section{La aprobación definitiva de la RPT}

En la Administración Local, la competencia para la aprobación y modificación de la RPT respectiva radica en el Pleno, artículos 22 y 33.2 de la Ley 7/1985, de 2 de abril, reguladora de las Bases del Régimen Local; el artículo 22 establece que corresponden, en todo caso, al Pleno las siguientes atribuciones: La aprobación de la Plantilla de Personal y La Relación de Puestos de Trabajo, la fijación de las cuantía de las retribuciones complementarias fijas y periódicas de los funcionarios y el número y el régimen del personal eventual. Por lo tanto la RPT queda aprobada en pleno, siendo necesaria una minoría simple.

Una vez aprobada inicialmente, la RPT tendrá que ser sometida al trámite de información pública y, ante la ausencia de un plazo especialmente indicado, éste será establecido por el órgano de gobierno.

\section{La publicación o notificación de la RPT}

El artículo 15.3 de la Ley 30/1984, de 2 de agosto, de medidas para la Reforma de la Función Pública dice que las RPT serán públicas.

El artículo 127 del Texto refundido de disposiciones vigentes en materia de Régimen Local (TR), aprobado por Real Decreto Legislativo 781/1986, de 18 de abril, determina que se hará la publicación íntegra de la RPT en el Boletín Oficial de la Provincia, junto con el resumen de los presupuestos.

Así pues, no es suficiente la publicación en el tablón de anuncios del ayuntamiento, aunque la RPT es una norma de carácter interno y sólo afecta al personal de la Entidad y no a los ciudadanos en general, afecta a intereses del personal total más allá del personal en activo, y son sujetos interesados en ella el personal excedente, suspenso, etc., así como el personal de las restantes Entidades locales e incluso de las restantes Administraciones Públicas, en la medida en la RPT adopta decisiones sobre movilidad interadministrativa que los convierte en sujetos interesados ${ }^{40}$.

\section{Remisión a la Administración del Estado}

El artículo 128 del Texto refundido de disposiciones vigentes en materia de Régimen Local, aprobado por Real Decreto Legislativo 781/1986, de 18 de abril, determina que una vez aprobada la RPT, se remitirá una copia a la Administración General del Estado y, en su caso, a la de la Comunidad Autónoma respectiva, dentro de un plazo de 30 días. La remisión ha de hacerse en concreto a la Dirección General para la Administración Local (Subdirección General de Función Pública Local).

Hay otros trámites que aunque no son obligatorios por ley, sí son muy recomendables para el buen fin de la RPT.

40 CORRAL VILLALBA, Juan (2001).

REALA, Nueva Época, - N. ${ }^{\circ}$ 5, enero-junio 2016 - ISSN: 1989-8975 - DOI: 10.24965/reala.voi5.10349 


\section{Crear un clima de confianza para elaborar la RPT}

Es necesario un clima favorable entre al personal para poder confeccionar una RPT. El personal debe ser informado de que a través de la RPT se intentará afrontar las situaciones precarias de los puestos de trabajo (el decrecimiento de efectivos, sobrecarga de trabajo, existencia de tareas no asignadas de forma clara, agravios comparativos en retribuciones o cargas de trabajo, etc.). Esto ayudará a vencer la resistencia al cambio por parte del colectivo, esta labor debe ser llevada a cabo por los responsables de la organización antes de iniciarse la RPT. Este clima debe ser mantenido y potenciado a lo largo de todo el proceso.

Es necesario que el personal no perciba la RPT como una amenaza a su seguridad, a sus retribuciones y a su status. Hay que transmitir la idea de que mejorará algún aspecto de su status, clarificará más de uno y objetivará la mayoría de ellos ${ }^{41}$.

\section{La Formación o información previa del personal}

Disminuir la resistencia del colectivo y conseguir una cierta colaboración fluida es más fácil si el personal es informado de los problemas que se pretenden abordar y de la importancia de la RPT. Por lo tanto debe dotarse al personal de la organización con información específica sobre la misma al comienzo de la elaboración. En esta fase de formación o explicación debe exponerse la filosofía y fines globales del proceso, las distintas fases y el calendario aproximado de realización.

\section{Implicación del equipo directivo}

La máxima garantía de que la RPT avance y finalice, es el respaldo decidido del equipo de gobierno de la Administración. Ya que es u proceso complejo, lento y largo, cuyas ventajas no se ven a primera vista, cuesta dinero y puede crear agravios y molestias concretas.

\section{La ejecución de la RPT}

Una vez elaborada, aprobada y publicada, entra en vigor y debe ser puesta en práctica. Siendo de obligado cumplimiento en todas sus partes, vinculando a la Administración y, en cuanto ha sido negociada, también a la parte social.

\section{Duración en el tiempo}

La RPT como norma que es, puede ser modificada o sustituida para evitar que ésta quede obsoleta, y deje de responder a las necesidades para las que ha sido creada. Las organizaciones con el transcurso del tiempo sufren modificaciones como la redistribución de funciones, características y denominación de los puestos, creación o supresión de estos, etc. Por esto es necesario un procedimiento de modificación de la RPT.

Ahora bien, aunque la Administración goza de iniciativa permanente para modificar la RPT y tal capacidad de modificación pertenece al ámbito de propio de la «potestad autoorganizativa», debe tenerse en cuenta que la modificación frecuente desfigura el papel planificador de la RPT y la convierte en un instrumento de pura oportunidad $^{42}$.

La iniciativa de modificación puede partir de las unidades de la organización en respuesta a necesidades, pero también puede surgir por parte del personal, de forma individual o conjunta. No todas las propuestas rematarán en la creación de un expediente de modificación.

El procedimiento de modificación de la RPT es muy parecido al de su elaboración. El expediente de modificación debe ser motivado; cualquier modificación debe ser negociada; la aprobación corresponde al órgano competente, es decir, al Pleno; y por último, una vez aprobada debe procederse a su publicación.

\section{VENTAJAS Y LIMITACIONES DE LA RPT}

La elaboración de una RPT tiene sus ventajas. Hay una mayor flexibilidad de la organización, adaptación de las tareas a las «necesidades de los servicios». Dota a la entidad de clarificación organizativa, se produce el análisis de duplicidades y redundancias, se identifica qué valor aporta cada puesto. Se pueden crear, modificar o suprimir puestos de trabajo, de forma que estos estarán concretados por la RPT. Con ella se definen las familias profesiona-

41 CORRAL VILLALBA, Juan (2001).

42 Villoria Mendieta, Manuel y del Pino Matute, Eloísa (1997).

REALA, Nueva Época, - N. ${ }^{\circ}$ 5, enero-junio 2016 - ISSN: 1989-8975 - DOI: 10.24965/reala.voi5.10349 
les comunes que permitan abordar proyectos de gestión homogéneos. La RPT dota a la organización de perfiles profesionales de los puestos; y se concreta la redistribución, recolocación y reubicación de efectivos. Aunque es necesario un cierto margen reglado de flexibilidad. También se determina el procedimiento de provisión de cada puesto de trabajo y se fijan los colectivos que pueden acceder a cada puesto. El concepto de puesto permite objetivar la toma de decisiones, evitando el personalismo ${ }^{43}$. Con la RPT queda definido el grado de movilidad interadministrativa, es decir, que los puestos de la entidad puedan cubrirse con personal de otras administraciones. Se definen funciones en exclusiva. La RPT podrá determinar los cuerpos o escalas que pueden desempeñar en exclusiva puestos concretos.

En relación a las retribuciones la RPT aplica un nivel concreto de complemento de destino a cada puesto, así como un complemento específico a aquellos que determine la RPT.

Es un instrumento de planificación comparando los puestos que existen con los que deben existir.

En cuanto al personal la RPT es de importancia primordial para las personas en la medida en que los puestos están ocupados por personas y éstas se benefician de las características del puesto; retribuciones, contenidos y requisitos de y para cada puesto.

Para el personal la RPT supone la concreción de sus perspectivas, la seguridad y la garantía de sus derechos y posibilidades. Los derechos del personal, sobre todo los retributivos y de carrera tienen una concreción y delimitación bastante precisa en la RPT, reduciendo el poder discrecional de la Administración.

La RPT es un instrumento esencial para concretar el status, entendido como el conjunto de derechos y deberes del personal en los siguientes aspectos.

Desde el punto de vista del trabajador también tiene sus ventajas, ya que permite el conocimiento por parte de cada ocupante las responsabilidades y funciones a ejecutar en el puesto. El personal conoce las condiciones y riesgos de su puesto de trabajo. Quedan determinadas las necesidades de aprendizaje para el desarrollo del mismo. Y crea un clima laboral favorable entre los miembros del colectivo y mejora de los flujos de información.

Por otra parte, otra gran ventaja es que la plantilla no se verá reducida arbitrariamente, los puestos reflejados en la relación de puestos deberán estar siempre cubiertos. Lo que da cierta seguridad laboral al personal.

Es importante reflejar que la RPT aunque es fundamental para establecer una buena relación de los puestos de trabajo en las organizaciones públicas tiene sus limitaciones; ya que la RPT es la valoración de los puestos de trabajo, independientemente de la persona que detente el cargo, no se tiene en cuenta la productividad del trabajador. «Es un sistema de contenidos mínimos, pues la descripción del cuerpo incorporada es básica. Con ello se pierde información estratégica clave para la promoción, evaluación del rendimiento, compensación o selección» ${ }^{44}$.

Por otra parte, la RPT puede provocar un efecto negativo para el buen funcionamiento de la organización pues puede llevar a que los trabajadores se encasillen en sus funciones, es decir, al fijar las funciones propias de cada puesto de trabajo es posible que las personas que los detenten limiten su labor a aquellas funciones que establezcan en la RPT de una manera muy rígida, lo que puede llevar a la ineficiencia y el conflicto con superiores y/o compañeros. Para ellos es necesario establecer un elemento corrector que nos aleje del encasillamiento de las funciones, por nuestra parte hemos salvado este escollo introduciendo para todos los puestos la función a mayores de «realizar cualquier otra función que le sea encomendada por sus superiores en el ámbito de sus competencias».

El modelo de RPT puede ser objeto de una fuerte politización o personalización, en algunos casos puede darse que las personas con poder político o buenas relaciones personales obtengan RPT adecuadas a sus intereses y por el contrario aquellas personas que carezcan de este poder o relaciones no consigan esos objetivos a pesar de que su organización los necesite. Por lo tanto hay que huir de esta politización, la RPT ha de ser realizada por expertos independientes.

Otra limitación de carácter político es la voluntad por parte del Órgano de Gobierno de aprobar finalmente la RPT. El producto final de la elaboración de la misma, no siempre es lo esperado por parte del Gobierno Local, puede darse que suponga un alto coste presupuestario o que ciertos puestos estén detentados por gente poco productiva (la RPT analiza el puesto, no a la persona) y se produzca un conflicto entre la retribución del puesto tras la valoración y lo que se considera que esa persona deba cobrar en relación a su productividad. El Órgano de Gobierno puede decidir aprobar sólo la relación de puestos, sin tener en cuenta las valoraciones, y por lo tanto no

43 Cuenca CerverA, J. Javier (2004): “La Dirección de Recursos Humanos en los Pequeños Ayuntamientos”. VI Jornadas Canarias de Administración Local. Santa Cruz de La Palma: 12 de mayo de 2004.

44 Villoria MendietA, Manuel y del Pino MATUTE, Eloísa (1997).

REALA, Nueva Época, - N. 5, enero-junio 2016 - ISSN: 1989-8975 - DOI: 10.24965/reala.voi5.10349 
modificar los complementos específicos de los puestos, o aplicarla de modo que a cada puesto se le atribuya una retribución específica según la valoración previa.

\section{LA IMPLANTACIÓN DE UNA RPT EN LA ADMINISTRACIÓN LOCAL: CASO EMPÍRICO}

A partir de este punto pasaremos a explicar nuestra metodología de trabajo. Para ello vamos a utilizar un caso empírico real donde se han modificado los datos de carácter económico y personal, el de un pequeño ayuntamiento ubicado en España de 9.000 habitantes. Ha de decirse que los datos aportados a continuación y en los anexos no son reales, si no creados con el fin de clarificar nuestra metodología, aunque no han sido seleccionados de manera arbitraria, siguen la lógica de nuestras experiencias previas en las entidades locales.

\section{Vl.1. Descripción de los puestos de trabajo}

La metodología utilizada en cierta medida es la habitual y definida anteriormente para la puesta en marcha de una RPT, el primer paso es la descripción de los puestos de trabajo. Se ha empezado por recoger toda la información disponible a cerca de la plantilla, ésta nos viene aportada por la entidad en la que se elabora la RPT. Posteriormente, y en conjunto con el órgano local se identifica y define los puestos necesarios, requisitos que deben tener las personas que los detentan, con el fin de conseguir el buen funcionamiento de la organización, y optimizar las capacidades organizativas de ésta. Es decir cuánta gente hay en plantilla, cuál sería el tamaño óptimo de ésta y las características de los puestos, cuál es su categoría, a qué área pertenece cada trabajador, de quién depende y quiénes dependen de él, qué funciones realizan, qué estudios han cursado, cuánto tiempo llevan realizando esas funciones, dónde se localiza su puesto de trabajo, cuál es su jornada laboral, en qué condiciones trabajan, etc.

Por tanto se necesita definir un organigrama, ubicando los puestos dentro del mismo (véase Anexo 1). El primer nivel, con dos dígitos, Corresponde al del área, muy en línea con la estructura política, de tal manera que en el documento final de la RPT no ha de figurar aunque exista una trazabilidad con los departamentos y secciones. La codificación es parlante, es decir, que se parte de siete grandes áreas con dos dígitos cada una de tal manera que se podría llegar a 99. El segundo nivel, se relaciona con el primero de tal manera que se compone de cuatro dígitos, los dos primeros nos indican el área y los siguientes diferencian los departamentos. Así, partiendo del área de hacienda, seguridad, tráfico y régimen interior, colgaría el departamento de hacienda, siendo su código 01 (área) 01 (departamento), Seguridad y tráfico sería el 01 (área) 02 (departamento). Esto nos llevaría al tercer nivel que sería la sección, en el cual se reflejaría el de secretaría, que sería 01 (área) 01 (departamento) 01 (sección).

En el anexo 2, se describe la ficha de cada puesto de trabajo reflejándose su posición en el organigrama. Se debe resaltar que las variables que describen los puestos de trabajo, deben ser lo más objetivas posible ya que eso facilitará la posterior valoración de los puestos de trabajo. Otro campo que se precisa determinar es establecer la relación laboral, es decir si se trata de personal eventual, fijo o funcionario. El grupo profesional al que pertenece, según sea personal laboral o funcionario, cuya clasificación se puede apreciar en la tabla 4.

TABLA 4: GRUPO PROFESIONAL

\begin{tabular}{ccl}
\hline $\begin{array}{c}\text { Grupo Personal } \\
\text { Laboral }\end{array}$ & $\begin{array}{c}\text { Grupo } \\
\text { Funcionarios }\end{array}$ & \multicolumn{1}{c}{$\begin{array}{c}\text { Grupo } \\
\text { de Titulación }\end{array}$} \\
\hline 1 & A & Título de doctor, licenciado o graduado, ingeniero, arquitecto o equivalente \\
\hline 2 & B & $\begin{array}{l}\text { Título de ingeniero técnico, diplomado universitario, arquitecto técnico, } \\
\text { formación profesional de } 3 .^{\circ} \text { grado o equivalente }\end{array}$ \\
\hline 3 & C & Título de bachillerato, formación profesional de $2 .^{\circ}$ grado o equivalente \\
\hline 4 & D & $\begin{array}{l}\text { Título de graduado escolar, formación profesional de } 1 .^{\circ} \text { grado o } \\
\text { equivalente }\end{array}$ \\
\hline 5 & E & Certificado de escolaridad \\
\hline
\end{tabular}

Fuente: Elaboración propia.

El sistema de acceso, indica la forma de incorporación al puesto de trabajo, que puede ser por libre designación, concurso oposición u oposición. El número de plazas, refleja el número de puestos a cubrir. Otro variable a

REALA, Nueva Época, - N. 5, enero-junio 2016 - ISSN: 1989-8975 - DOI: 10.24965/reala.voi5.10349 
determinar, es horario laboral, según si la jornada de trabajo es continua, partida o turnos y se indica el horario concreto. Localización, es la ubicación donde se desempeña habitualmente el puesto de trabajo.

En el apartado de requisitos del puesto, se ha de definir la titulación requerida para el puesto, el nivel de estudios necesario para poder realizar las labores del mismo. Si hubiera especialidad hay que definirla, así como los conocimientos específicos necesarios para su puesto de trabajo. Otro factor a definir es la experiencia requerida para el desempeño del puesto. Entrando en algo más general, habría que establecer la misión, y un mayor detalle como son las funciones principales del puesto de trabajo.

En referencia a las condiciones en su puesto de trabajo, otro término a describir y valorar sería especificar donde se desarrolla el trabajo, si éste se desarrolla principalmente en el interior o en el exterior. Los ruidos y vibraciones es otra condición que afecta al desempeño del puesto de trabajo, que pueda haber en el puesto de trabajo, según la intensidad de los mismos. Para ir finalizando la ficha, tendríamos el factor peligrosidad del trabajo, la posibilidad de sufrir accidentes o contraer enfermedades como consecuencia de riesgos inherentes a las actividades del puesto; y por último, la penosidad del mismo, se refiere a circunstancias de incomodidad, desagrado, molestias o condiciones adversas, así otras condiciones a especificar por el trabajador.

En el último bloque se define por quién está descrito, la fecha de descripción, la fecha de anulación del puesto y si es sustituido por otro.

Una vez definida la ficha, se procede a rellenar previamente con la información que suministra la organización, para posteriormente entrevistarnos con todos los empleados, o uno por puesto, cuando existen puestos con las mismas funciones, junto al responsable del departamento de personal o en quien delegue, para consensuar la ficha descriptiva del puesto de trabajo, reflejada en el anexo 2. Con esta técnica nos aseguramos de que la información es correcta, queda verificada por el consenso entre el trabajador y su superior, con la mediación de un técnico independiente.

\section{VI.2. Valoración}

Una vez terminada la elaboración de las fichas, ya tenemos la información sobre los puestos de trabajo, por lo que nos disponemos a hacer la valoración de cada uno de ellos, ya que las actividades y características son distintas de unos a otros, debiéndose cuantificar esa diferencia de contenidos e importancia entre los puestos.

El método de valoración que se va a utilizar es el sistema de puntuación de factores y grados. Para esto hemos tenido que elegir los factores de valoración y seleccionar la serie de grados para cada factor. Los factores de valoración los hemos definido antes de la elaboración de la ficha, para poder recoger la información acerca de ellos, estos factores han sido elegidos por su importancia descriptiva del puesto de trabajo y por su cualidad cuantitativa, son fácilmente ponderables.

El siguiente paso es la graduación de los factores, es decir, asignar diferentes grados a cada factor según sean meritorios de menor o mayor puntuación (anexo 3), y todas las variables tienen una escala de 1 a 5 . Los elementos seleccionados serían el horario, pues es un hecho objetivo que las condiciones de los profesionales varían según sea un horario intensivo matutino o trabajar a turnos. Otro factor ponderable sería la titulación exigida al puesto, que va desde sin estudios hasta el nivel máximo requerido para el puesto como sería graduado o licenciatura universitaria. El tercer factor sería el de la experiencia previa requerida para el puesto. El cuarto factor considerado sería el de la responsabilidad, lo que supone comparativas entre la más baja (1 punto) y muy alta ( 5 puntos). El quinto factor que se ha utilizado es la peligrosidad, que va desde la más baja (1 punto) hasta alta ( 5 puntos). En este apartado se ha introducido la categoría circunstancialmente mayor, con esto se pretende que un puesto puede tener una peligrosidad baja, pero con circunstancias que elevan su nivel de peligrosidad. Por ejemplo, una persona de limpieza que tiene encargada la tarea de las ventanas, en esas circunstancias su nivel de riesgo aumenta respecto a otro puesto que no requiere dicho hecho. Así mismo se puede argumentar para la policía local, en un pequeño pueblo de España, ¿conlleva un alto riesgo?, en cambio sus circunstancias lo pueden exponer a un nivel de máxima peligrosidad. El sexto factor a considerar es la penosidad, hecho que afecta a las condiciones del puesto de trabajo. Por último, tendríamos la dificultad técnica del puesto de trabajo, que va desde baja hasta muy alta.

Definidas las variables y su escala, el peso de las mismas no tiene por qué ser el mismo, de tal manera que cinco meses de experiencia previa que puntúa cinco puntos, no es equiparable a una licenciatura o grado superior que conlleva 18 años de estudios. Por ello, se ha ponderado el peso de los factores, dado que es un tema de consenso, se propuso a cada miembro de un amplio equipo de trabajo que expusiese el peso que debería otorgársele a cada variable, siendo el resultado lo que se puede apreciar en la tabla 5, donde la titulación exigida, responsabilidad y dificultad técnica, pesa 8 veces más que la experiencia previa. 
TABLA 5: PONDERACIÓN DE FACTORES

\begin{tabular}{lccccc}
\hline Factores & Grados & Ponderación & \% ponderación & Puntuación mínima & Puntuación máxima \\
\hline 1. Horario & $1-5$ & 2 & $6,1 \%$ & 2 & 10 \\
\hline 2. Titulación exigida & $1-5$ & 8 & $24,2 \%$ & 8 & 40 \\
\hline 3. Experiencia & $1-5$ & 1 & $3,0 \%$ & 1 & 5 \\
\hline 4. Responsabilidad & $1-5$ & 8 & $24,2 \%$ & 8 & 40 \\
\hline 5. Peligrosidad & $1-5$ & 3 & $9,1 \%$ & 3 & 15 \\
\hline 6. Penosidad & $1-5$ & 3 & $9,1 \%$ & 3 & 15 \\
\hline 7. Dificultad Técnica & $1-5$ & 8 & $\mathbf{2 4 , 2 \%}$ & 8 & 40 \\
\hline \multicolumn{1}{c}{ Total } & & 33 & $\mathbf{1 0 0 , 0 \%}$ & 33 & 165 \\
\hline
\end{tabular}

Fuente: Elaboración propia.

Una vez se han identificado las variables, su escala y peso, se procede a valorar cada puesto capturando la información desde la ficha. Qué duda cabe que la traducción de una ficha a una valoración cuantitativa conlleva en algún caso un cierto elemento de subjetividad. Por ejemplo, ¿qué nivel de peligrosidad conlleva el puesto de electricista que a veces se sube a los postes de luz? ¿cuán responsable es el puesto de educadora social?. En cierta medida existe una correlación entre el nivel exigido para el puesto y su responsabilidad. Otro factor que trata de objetivarse en esta ponderación es el número de personas que dependen de un puesto, o el nivel en el organigrama. La dificultad técnica se determina de la descripción de las tareas, siendo el máximo exponente el puesto de secretario, interventor o tesorero.

El resultado de esta valoración técnica por departamento y puesto de trabajo se puede apreciar, a modo de ejemplo en el anexo 4. Ahora bien, como se ha explicado previamente el factor tiene un peso relativo diferente, de tal manera que para obtener la valoración ponderada de los puestos, se ha de multiplicar dichos puntos por el peso de cada factor (tabla 5), de tal manera que para el puesto administrativo del departamento de secretaría, el horario se multiplica por 2, la titulación por 8, así sucesivamente. El resultado del mismo queda reflejado en el anexo 5, donde se aprecia que los puestos más valorados son el de Inspector de Policía Local, Secretario, Interventor y Arquitecto, (ya que no tienen definido el de Tesorero en administración, sino sería muy parejo al de los otros habilitados nacionales), siendo las diferencia entre en el inspector y el resto, el horario y la peligrosidad. Si se usaran otras variables, otras ponderaciones u otras escalas, el resultado podría ser otro, como que el inspector de Policía estuviera por debajo del Secretario e Interventor. En todo caso, este modelo nos ofrece una coherencia, al ubicar dichos puestos en las primeras posiciones, frente a auxiliares administrativos, limpiadores/as, operarios/as y ordenanzas.

Una vez valorados los puestos desde un punto de vista técnico, hay que determinar el complemento específico del puesto, pues es necesario reflejarlo en la RPT. En el anexo 6, se puede apreciar la valoración económica y el desembolso que supondría para el ayuntamiento. Lo primero que hay que determinar es el valor que tiene cada punto reconocido en el anexo 5. Para ello, se identifican los puestos que hasta la fecha obtenían complementos específicos, denominado complemento antiguo. Se puede observar la gran disparidad en la percepción del complemento, de tal manera que algunos obtenían casi 20.000 euros $^{45}$, auxiliares administrativos que perciben $5.272,44$ euros, el arquitecto nada y sí en cambio el aparejador. Esta situación viene derivada del pasado donde los distintos responsables municipales otorgaban el complemento en base a la persona o para premiar actitudes personales o profesionales, pero no basada en una valoración del puesto de trabajo que desempeñaba. La ponderación del complemento antiguo tiene por objetivo la de obtener el valor económico del punto, el cual será el sumatorio entre los puntos ponderados de los que obtenían dicho complemento. Esta ratio asciende a 64,37 euros.

Obtenido el valor punto y los puntos por puesto, el nuevo complemento a percibir sería el resultado de multiplicarlos. Esto nos lleva a que todos los puestos tengan una valoración económica. Ahora bien, ¿se han de conceder complementos específicos a todos los puestos o se puede establecer un criterio de corte?.Esto es una decisión política, si se decide a partir de x puntos conceder el complemento o no, el modelo permite dicha opción. En esta metodología se han ponderado todos los puestos y se ha supuesto que todas tendrán su complemento específico en función del resultado obtenido.

45 Aunque son datos cambiados, sí existían diferencias de complementos injustificadas.

REALA, Nueva Época, - N. ${ }^{\circ}$ 5, enero-junio 2016 - ISSN: 1989-8975 - DOI: 10.24965/reala.voi5.10349 
Para aquellos que pasarían a percibir un nuevo complemento o éste sea superior, siempre y cuando el gobierno local tenga presupuesto para ello, con el informe favorable del interventor, empezarían a percibirlo, pero ¿qué pasa con los que percibían de más? ¿Se les ajusta al nuevo o en cambio se les mantiene de tal manera que a medida que se les suba el sueldo se le reduce el complemento? Esto sería o reducción de ingresos, o congelación de los mismos, siendo otra decisión política. Desde un punto de vista técnico se ha supuesto que no se reduce los ingresos a nadie, sino la congelación de los mismos y reducción del complemento a medida que se obtuvieran subidas salariales. Esto supone un desembolso para el ayuntamiento de $272.561,42 €$ frente a los 112.715,88 que venía haciendo, por tanto un aumento de percepciones para los trabajadores de $159.845,54$ que unido al coste de la seguridad social, pues es cotizable, se puede estimar en 210.000 euros de masa salarial para el ayuntamiento al año.

Otro aspecto relevante es que en alguna figura clave como Secretario e Interventor, verían reducidos sus complementos de manera considerable. Esto viene motivado por el modelo general que se ha establecido, pero al ser habilitados nacionales y por las peculiaridades de su puesto, también se podría excluirlos del modelo y mantener sus complementos específicos no en base a un conjunto de factores, sino en base al a complejidad específica de sus responsabilidades. En alguna RPT se ha intentado modelizar de tal manera que se justificaría la percepción de dichas figuras claves. Entendemos que eso es un error, pues llevaría a establecer criterios muy específicos que distorsionan el interés general de los puestos de trabajo y su valoración.

\section{CONCLUSIONES}

Existen muchas administraciones que no tienen realizada una Relación de Puestos de Trabajo, lo que conlleva que tengan un modelo basado en tareas poco claras, responsabilidades no definidas y el establecimiento de complementos específicos otorgados históricamente con criterios que no se ajustan a factores objetivos ni consensuados.

La RPT viene a paliar parte de estas deficiencias, pues ayuda a poner orden en una organización, identificando los puestos, definiendo los requisitos, la titulación, las funciones y hasta su valoración técnica y económica que determina el complemento específico y encuadramiento en un organigrama.

Ahora bien, la implantación de una RPT conlleva mucha dificultades, en primer lugar, supone un gran trabajo para la administración, reuniones con los afectados, negociación con el Comité de Empresa y por lo general la expectativa por parte de los trabajadores de que se les equipare su situación a otros que por circunstancias históricas pudieran tener unas condiciones específicas no acordes ni a su puesto ni a su situación actual. Es difícil valorar a la baja o quitar a una persona algo que no le corresponde, siendo la tendencia al revés.

En este artículo se plantea un modelo objetivo, pues descritos los puestos de trabajo, se establece una valoración basada en variables consensuadas entre el equipo de gobierno y el Comité de Empresa, las cuales se ponderan y se establece una escala para poder valorar cada puesto de trabajo. Además se calcula el valor de cada punto y se obtiene una nueva valoración económica que se compara con la anterior y permite calcular las diferencias. Este modelo ofrece diversas posibilidades de toma de decisiones, como si se establece un mínimo de puntos para la obtención del complemento económico. También se propone no eliminar complemento antiguo otorgado, sino congelar los ingresos del profesional siempre y cuando su nuevo complemento sea inferior al anterior. Y se recomienda dar un tratamiento diferencial, si fuera necesario a los puestos de Interventor e Secretario, pero nunca adecuar el modelo de valoración de la RPT a dichas circunstancias para justificar sus complementos, como ha ocurrido en algunos ayuntamientos lo que ha supuesto un rotundo fracaso.

Otra conclusión es que en ocasiones los sindicatos, trabajadores y Comité de Empresa, centran la negociación de la RPT en una subida salarial vía complemento, no siendo esa la esencia de la misma, pues como se trata de una Relación de Puestos de Trabajo en la que se ha de definir el complemento, pero este puede tener valor cero, no siendo necesario otorgárselo a todos los puestos, ni justificarlo en base a percepciones históricas no definidas en ningún modelo.

Por otro lado, algunos responsables de los ayuntamientos no habían calculado bien el impacto económico que a veces supone poner en marcha una RPT, o que esta valora puestos de trabajo y no personas, de tal manera que dentro del puesto puede haber profesionales con distinta productividad y que tendrían la misma valoración, teniendo la tentación de cambiar las variables del modelo para favorecer a un puesto frente a otro según quien ocupe dicho puesto, siendo un error este planteamiento.

Como conclusión final, a pesar de las dificultades de llevar a cabo una RPT que posiblemente no termine de gustar de todo a las partes, ayuda a mejorar la organización, clarificándola, haciéndola más transparentes, objetivizando los emolumentos y dificultando las arbitrariedades. 


\section{BIBLIOGRAFÍA}

AldomÁ BuIXADE, Josep (1996): Les relacions de Llocs de Treball de les administracions públiques, Cedecs, Barcelona.

ARROYO YANES, Luis Miguel (1994): La carrera administrativa de los funcionarios públicos. Editorial Tirant Lo Blanch. Valencia.

BALLART, Xavier y RAMió, Carles (2000): Ciencia de la Administración. Ed. Tirant lo Blanch. Valencia.

BAÑón MARTïNEZ, Rafael (1986): "Función Pública Local en España: Movilidad, carrera y profesionalización del personal." CIVITAS. Revista Española de Derecho Administrativo. Madrid.

BARRANCO, Francisco Javier (1993): Planificación estratégica de los recursos humanos. Del Marketing interno a la planificación. Madrid. Pirámide.

Bocinós RoıBoó, M. Inés (2006): “Instrumentos de Ordenación de Gestión de Recursos Humanos, Especial Referencia a la Administración Local”. Revista Cemci, n. ${ }^{\circ} 6$ enero-marzo.

- Boletín Oficial de la Provincia de Pontevedra, n. ${ }^{\circ}$ 141, viernes 22 de junio de 2011.

CARrillo BARroso, Ernesto (1991): Gestión de Recursos Humanos, presupuestación y hacienda local en España. Madrid. Instituto de Estudios Fiscales.

CASTILLO BLANCO, Federico (1998), coordinador: Situación actual y tendencias de la función pública española. Comares-CEMCI. Granada.

CLIFFORD, James P. (1994): “Job Analysis: Why do Do It and How Should It be Done?”. Public Pesonnel Management, vol. 23, n. 21994.

COOPERS Y LYBRAND (1996): El Capital Humano en la Empresa. Cuadernos cinco días.

CORDERO SAAVEDRA, Luciano (2002) "La controvertida naturaleza jurídica de las relaciones de puestos de trabajo en las administraciones públicas", Actualidad Administrativa 26.

CoRRAL VILLALBA, Juan (2000): Manual de Gestión del Personal de la Administración Local, Civitas.

CORRAL VILLALBA, Juan (2001): Cómo hacer la valoración de puestos de trabajo en un Ayuntamiento: La Relación de Puestos de Trabajo, Civitas.

Cruz HerRerA, M. ${ }^{a}$ Cristina (2013): “La Relación de Puestos de Trabajo. Una Crítica a la Situación Actual”. Revista Cemci, n. ${ }^{\circ} 19$ abril-junio 2013.

CuencA CerverA, J. Javier (2004): “La Dirección de Recursos Humanos en los Pequeños Ayuntamientos". VI Jornadas Canarias de Administración Local. Santa Cruz de La Palma: 12 de mayo de 2004.

De VICENTE Domingo, Ricardo (1997): El puesto de trabajo en el derecho de la función pública. Tirant lo Blanch, Valencia.

- Decreto Foral Legislativo 251/1993, de 30 de agosto, del Texto Refundido del Estatuto del Personal al Servicio de las Administraciones Públicas de Navarra.

- Decreto Legislativo 1/1991, de 19 de febrero, por el que se aprueba el Texto Refundido de la Ley de Ordenación de la Función Pública de la Comunidad Autónoma de Aragón.

- Decreto Legislativo 1/1997, de 31 de octubre, por el que se aprueba la refundición en un texto único de los preceptos de determinados textos legales vigentes en Cataluña en materia de función pública.

- Decreto Legislativo 1/2001, de 26 de enero, por el que se aprueba el Texto Refundido de la Ley de la Función Pública de la Región de Murcia artículos 17, 18 y 19.

FERNÁNDEZ LóPEZ, Ángela Maday (2005): “Análisis y Descripción de los Puestos de Trabajo”. Revista Gestiópolis.

FONDEVILA ANTOLíN, Jorge (1990): "Nuevos aspectos sobre la naturaleza de las estructuras orgánicas y relacione.s de puestos de trabajo: Jurisprudencia reciente", Revista Vasca de Administración Pública 28.

GARCíA De ENTERRíA, Eduardo (1999): “La organización y sus agentes: revisión de estructuras.” En La Administración española: estudios de ciencia administrativa. Civitas. Madrid (e.o. 1961).

GARCíA de ENTERRÍA, Eduardo; FERnÁNDEZ, Tomás-Ramón (2002): Curso de Derecho Administrativo I, Madrid.

- Ley 30/1984, de 2 de agosto, Medidas para la Reforma de la Función Pública.

- Ley $7 / 1985$, de 2 de abril, de Bases del Régimen Local.

- Ley 6/1985, de 28 de noviembre, de Ordenación de la Función Pública de la Junta de Andalucía.

- Ley 3/1985, de 26 de diciembre, de Ordenación de la Función Pública de la Administración del Principado de Asturias.

- Ley $1 / 1986$, de 10 de abril, de la Función Pública de la Comunidad de Madrid.

- Ley 2/1987, de 30 de marzo, de la Función Pública Canaria.

- Ley 6/1989, de 6 de Junio, de la Función Pública Vasca.

- Ley 3/1990, de 29 de junio, de Función Pública de la Administración Pública de la Comunidad Autónoma de la Rioja.

- Ley 4/1993, de 10 de marzo, reguladora de la Función Pública de la Administración de la Diputación Regional de Cantabria. 
- Ley 7/2005, de 24 de mayo, de la Función Pública de Castilla y León.

- Ley 21/2006, de 20 de junio, por la que se modifica la Ley 9/1987, de 12 de junio de Órganos de Representación (LOR).

- Ley 10/2010, de 9 de julio, de la Generalitat, de Ordenación y Gestión de la Función Pública Valenciana.

- Ley 4/2011, de 10 de marzo, del Empleo Público de Castilla-La Mancha.

- Ley 9/2012, de 19 de julio, de modificación de la ley 3/2007, de 27 de marzo, de la función pública de la Comunidad Autónoma de las Illes Balears.

- Ley 13/2015, de 8 de abril, de Función Pública de Extremadura.

- Ley 2/2015, del 29 de abril, del Empleo público de Galicia.

LLISET BorReLL, Francisco y GRAU ÁviLA, Sebastián (1992): "La Función Pública Local." En Informe sobre el Gobierno Local. Madrid. MAP y Fundación Pi y Sunyer.

MAURI MAJós, Joan (2003): "Las relaciones de Puestos de Trabajo y la Gestión de la Función Pública Local”. Estudios QDL. Fundación Democracia y Gobierno Local.

Moreu CARbonelL, Elisa (1997): "Las Relaciones de Puestos de Trabajo en el Proceso de Reforma de las Administraciones públicas". Seminario de Derecho Administrativo, Universidad de Zaragoza. Y en Revista de Administración Pública.

MOREY JUAN, Andrés (2000): "Las relaciones de puestos de trabajo: su naturaleza jurídica y problemática", Revista General del Derecho.

Palomar Olmeda, Alberto (1996): Derecho de la función pública. Dykinson, Madrid.

PeÑA Molina, Marcos (2014): "La nueva doctrina del TS sobre la Relación de Puestos de Trabajo. Aplicación práctica en el ámbito local”. Revista Derecho Local, 1 de julio de 2014.

- Real Decreto Legislativo 781/1986, de 18 de abril, por el que se aprueba el texto refundido de las disposiciones legales vigentes en materia de Régimen Local.

- Real Decreto Legislativo 3/2011, de 14 de noviembre, por el que se aprueba el texto refundido de la Ley de Contratos del Sector Público.

- Real Decreto Legislativo 5/2015, de 30 de Octubre, por el que se aprueba el texto refundido de la Ley del Estatuto Básico del Empleado Público.

SÁNCHEZ MORÓN, Miguel (1998): "Balance de la Función Pública”. En La posición institucional de la Administración Local ante el Siglo XXI. IVAP. Oñati.

SÁNCHEZ MOTOS, Enrique (1996): Análisis del funcionamiento de las organizaciones. Mimeo.

- Sentencia de 2 de diciembre de 2010 (rec. 4775/2009) de la Sala de lo Contencioso Administrativo del Tribunal Supremo.

- Sentencia de 5 de febrero de 2014 (EDJ 2014/31816) del Contencioso-Administrativo del Tribunal Supremo.

Villoria Mendieta, Manuel y del Pino MATUTE, Eloísa (1997): Manual de Gestión de Recursos Humanos en las Administraciones Públicas, Madrid, TECNOS. 


\section{ANEXO 1: ORGANIGRAMA: ÁREA/DEPARTAMENTO/SECCIÓN, CODIFICADO}

\begin{tabular}{|c|c|}
\hline Código & Denominación \\
\hline 01 & Hacienda, Seguridad y Tráfico, e Régimen Interior \\
\hline 0101 & Hacienda \\
\hline 010101 & Secretaría \\
\hline 010102 & Intervención \\
\hline 010103 & Tesorería \\
\hline 0102 & Seguridad y Tráfico \\
\hline 010201 & Policía Local \\
\hline 0103 & Régimen Interior \\
\hline 010301 & Registro \\
\hline 010302 & Padrón \\
\hline 02 & Cultura \\
\hline 0201 & Cultura \\
\hline 020101 & Cultura \\
\hline 03 & Juventud, Normalización Lingüística y Comunicación Social \\
\hline 0301 & Juventud \\
\hline 030101 & Juventud \\
\hline 04 & Bienestar social, Igualdad, Educación y Sanidad \\
\hline 0401 & Bienestar Social \\
\hline 040101 & Bienestar Social \\
\hline 0402 & Igualdad \\
\hline 040201 & Igualdad \\
\hline 0403 & Educación \\
\hline 040301 & Educación \\
\hline 0404 & Sanidad \\
\hline 040401 & Sanidad \\
\hline 05 & Deportes, Turismo, Personal, Empleo, Comercio e Industria \\
\hline 0501 & Deportes \\
\hline 050101 & Deportes \\
\hline 0502 & Turismo e Empleo \\
\hline 050201 & Turismo e Empleo \\
\hline 0503 & Personal \\
\hline 050301 & Personal \\
\hline 06 & Urbanismo, Obras, Servizos, e Medio Ambiente \\
\hline 0601 & Urbanismo \\
\hline 060101 & Urbanismo \\
\hline 0602 & Obras \\
\hline 060201 & Obras General \\
\hline 060202 & Electricidad \\
\hline 060203 & Albañilería \\
\hline 060204 & Fontanería \\
\hline 060205 & Jardinería \\
\hline 0603 & Servicios \\
\hline 060301 & Servicio Limpieza \\
\hline 0604 & Medio Ambiente \\
\hline 060401 & Medio Ambiente \\
\hline 0605 & Catastro \\
\hline 060501 & Catastro \\
\hline 07 & Medio Rural \\
\hline 0701 & Medio Rural \\
\hline 070101 & Medio Rural \\
\hline
\end{tabular}

Fuente: Elaboración propia en base a estructura del ayuntamiento

REALA, Nueva Época, - N. ${ }^{\circ}$ 5, enero-junio 2016 - ISSN: 1989-8975 - DOI: 10.24965/reala.voi5.10349 
ANEXO 2. FICHA DESCRIPTIVA DEL PUESTO DE TRABAJO

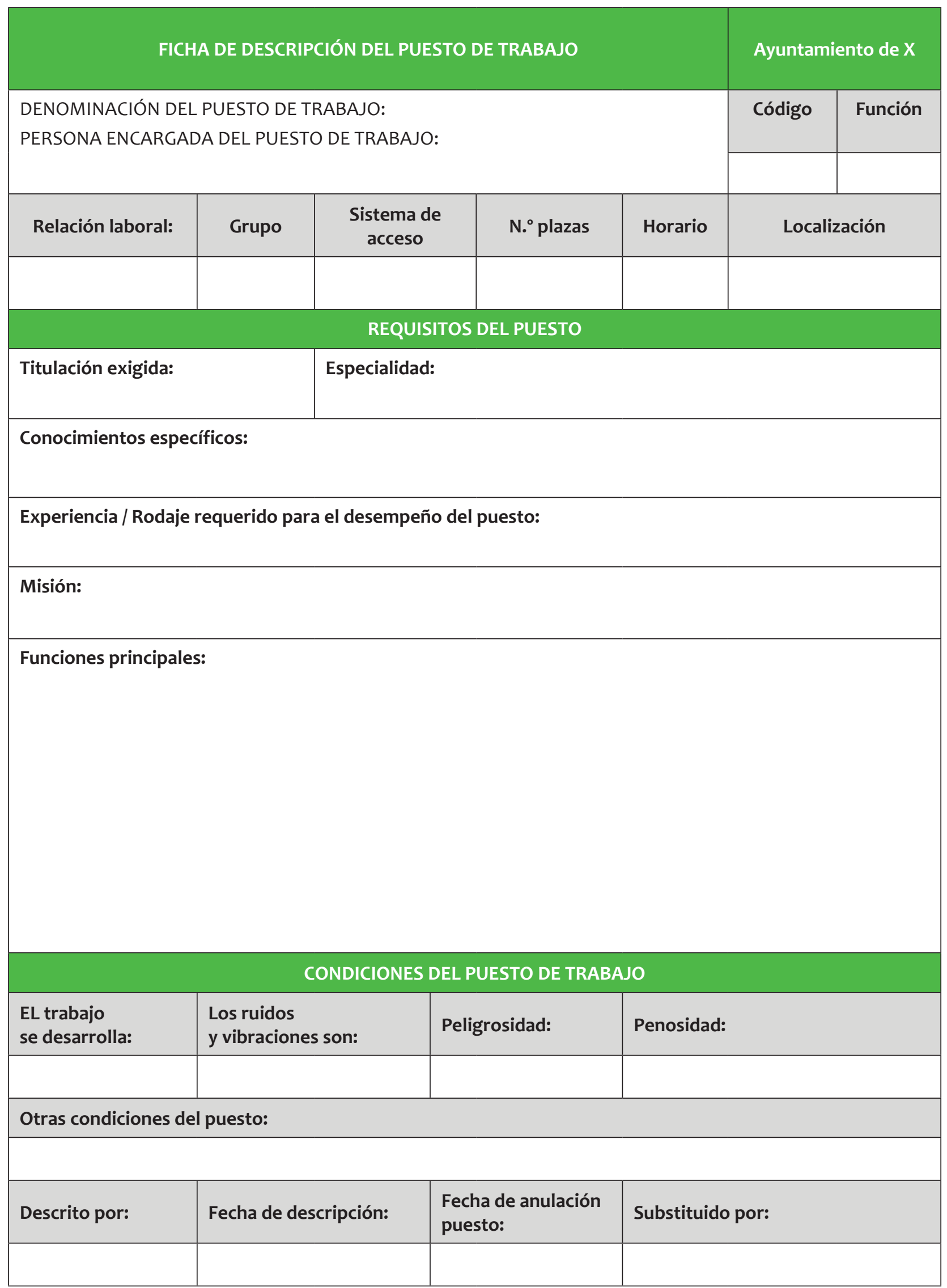

Fuente: Elaboración propia 


\section{ANEXO 3: PONDERACIÓN DE LOS FACTORES DE LA RPT}

1. Horario

Valor

Intensivo matutino

Intensivo matutino

Partido fijo

Flexible

A turnos

2. Titulación exigida

Valor

Sin estudios

Graduado en ESO

Bachillerato o FPI

Diplomado / FP II

Graduado o licenciado

3. Experiencia

$<1$ meses

1 meses - 2 meses

2 meses - 3 meses

3 meses - 4 meses

$>5$ meses

4. Responsabilidad

Baja

Media

Media Alta .

Alta

Muy alta

5. Peligrosidad

Valor

Baja

Baja circunstancialmente mayor

Media

Media circunstancialmente mayor

Alta

Baja

Media baja .

Media

Media alta

Alta

7. Dificultad técnica

Baja

Media

Media Alta .

Alta

Muy alta 


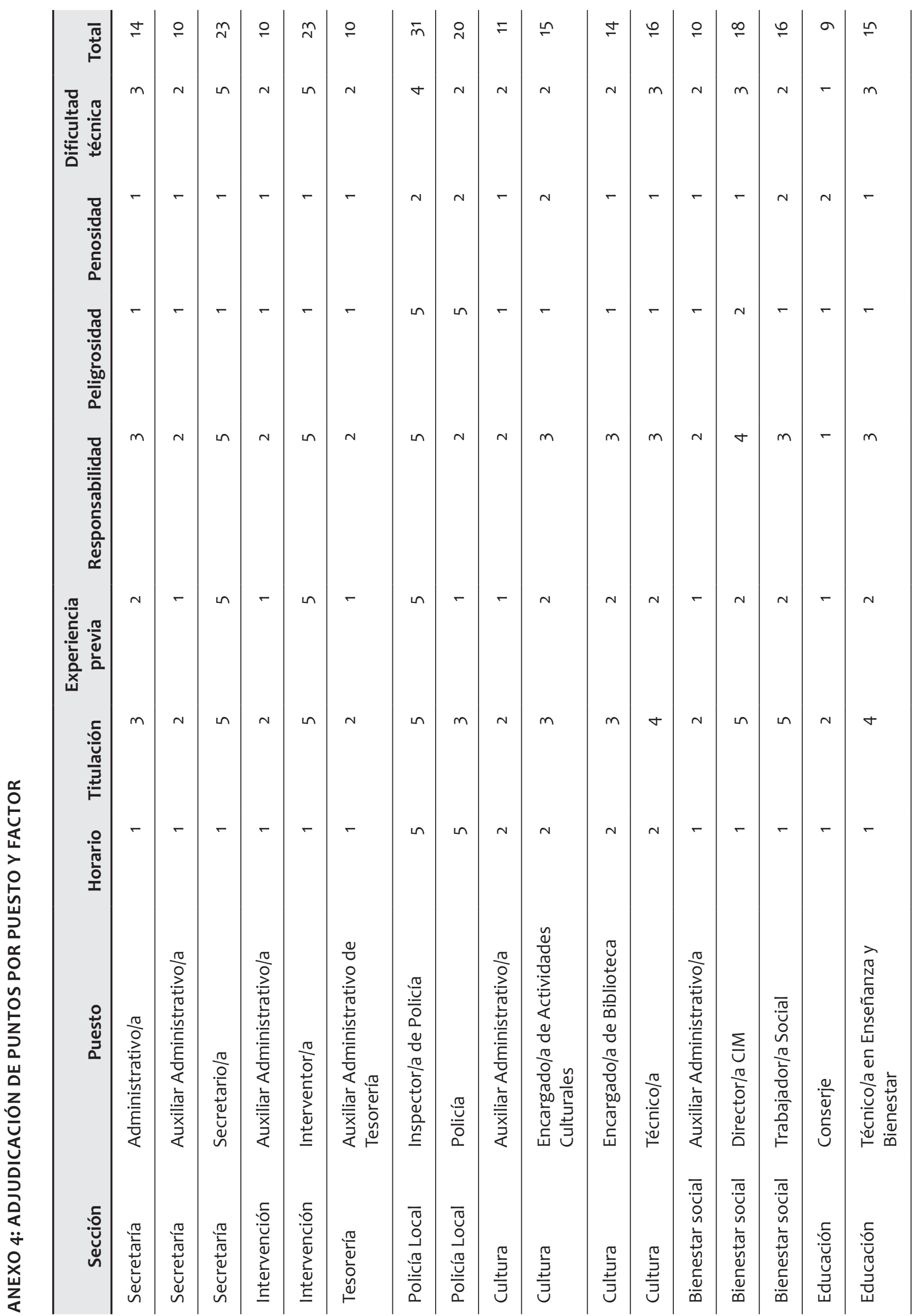




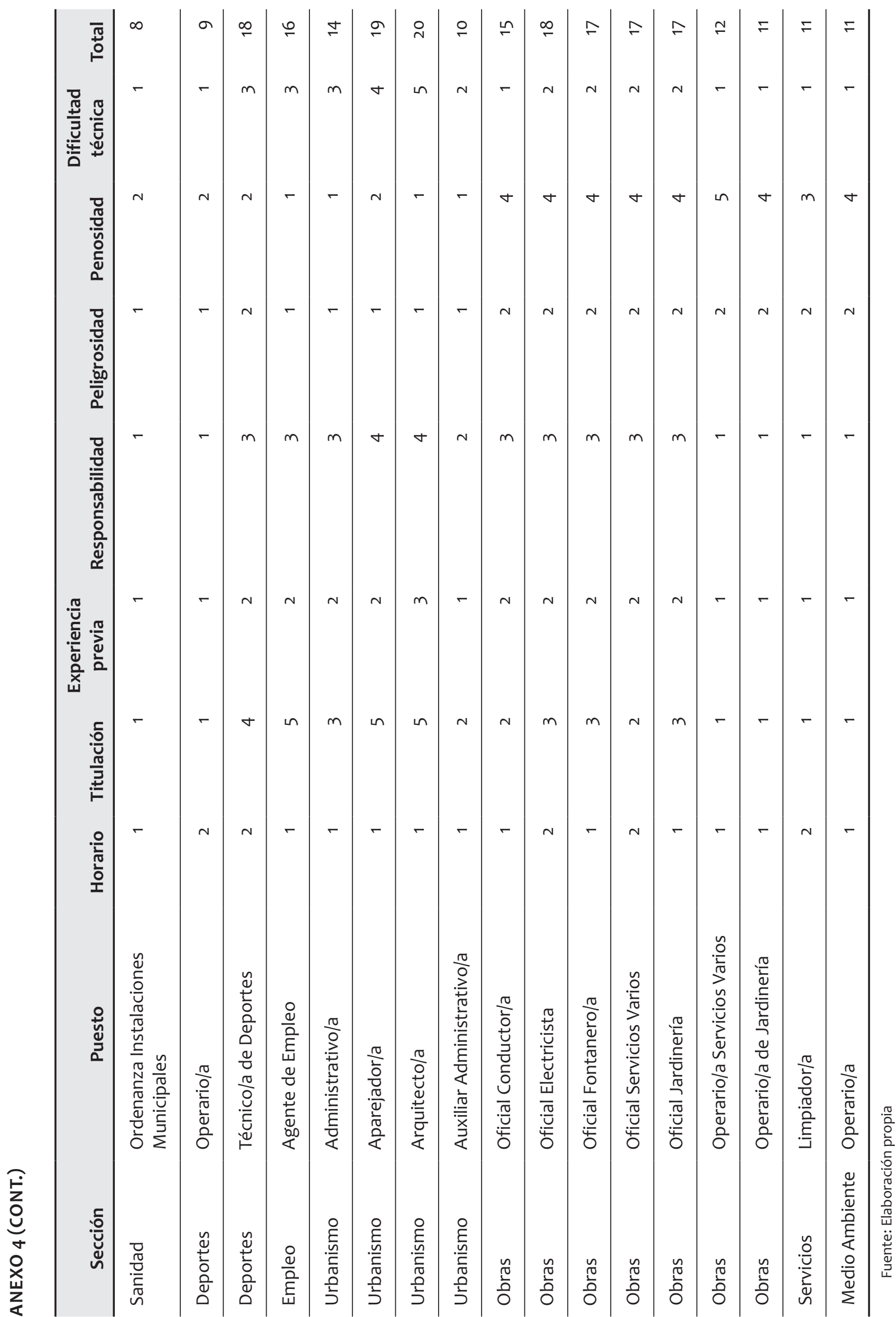




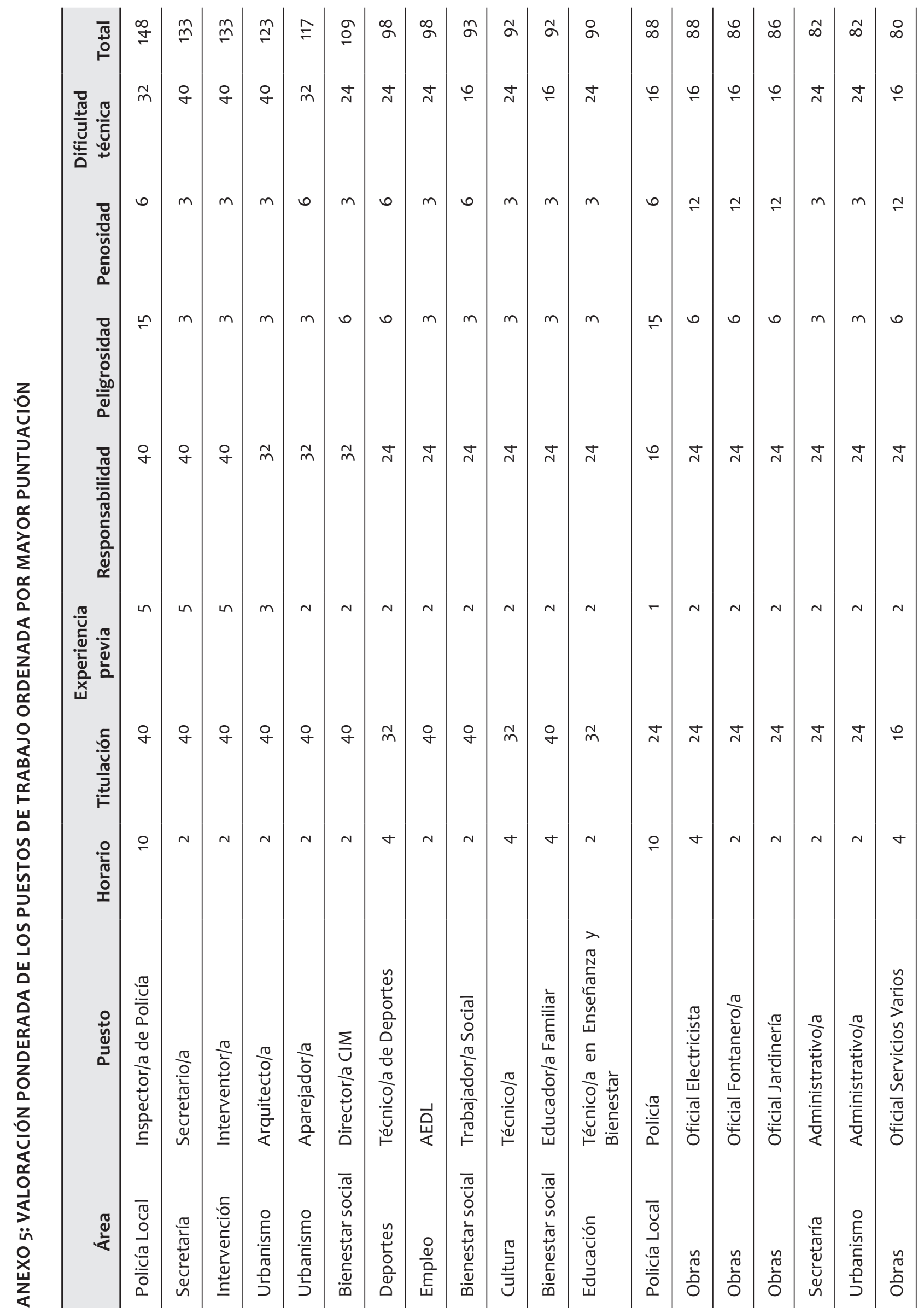




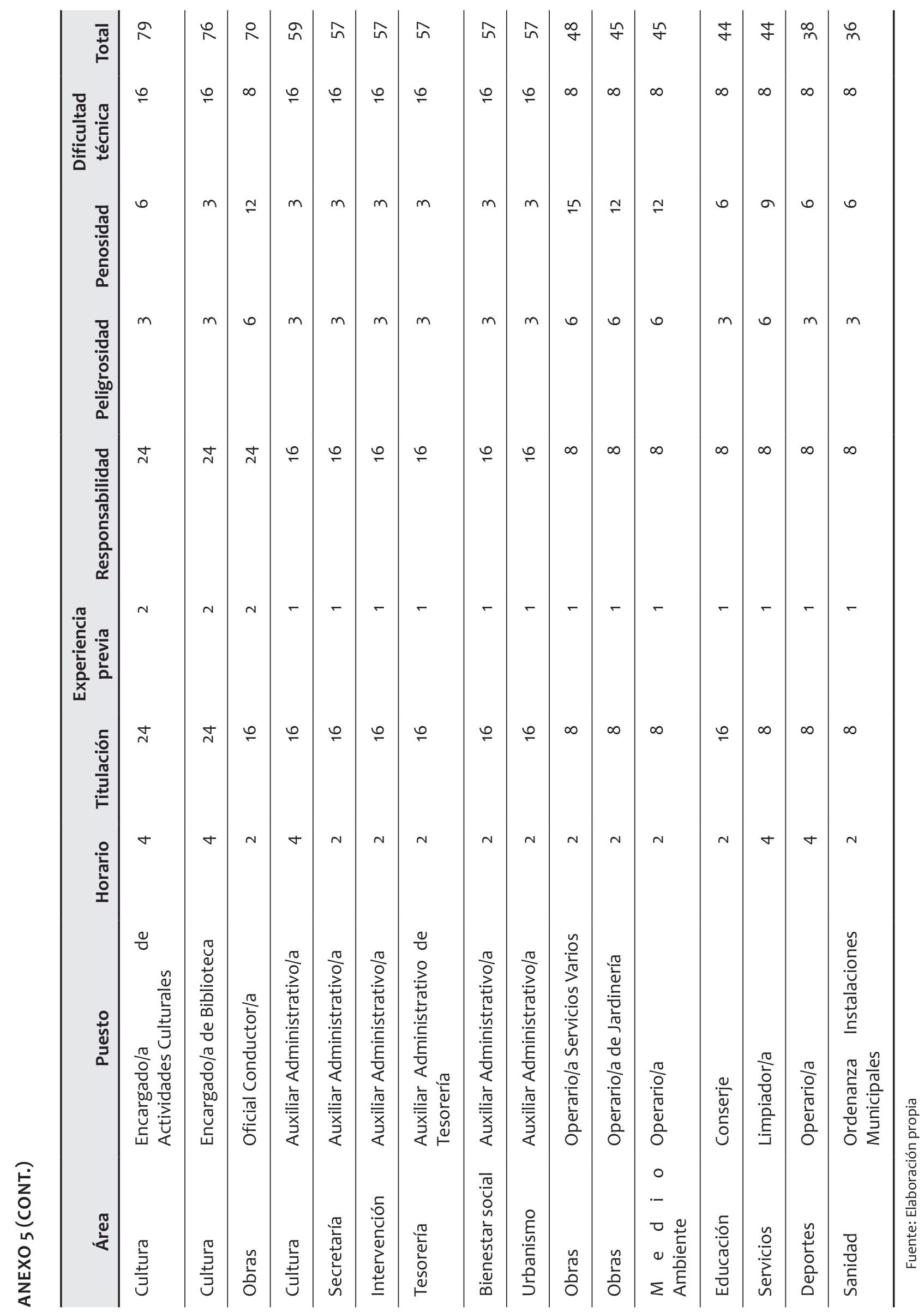




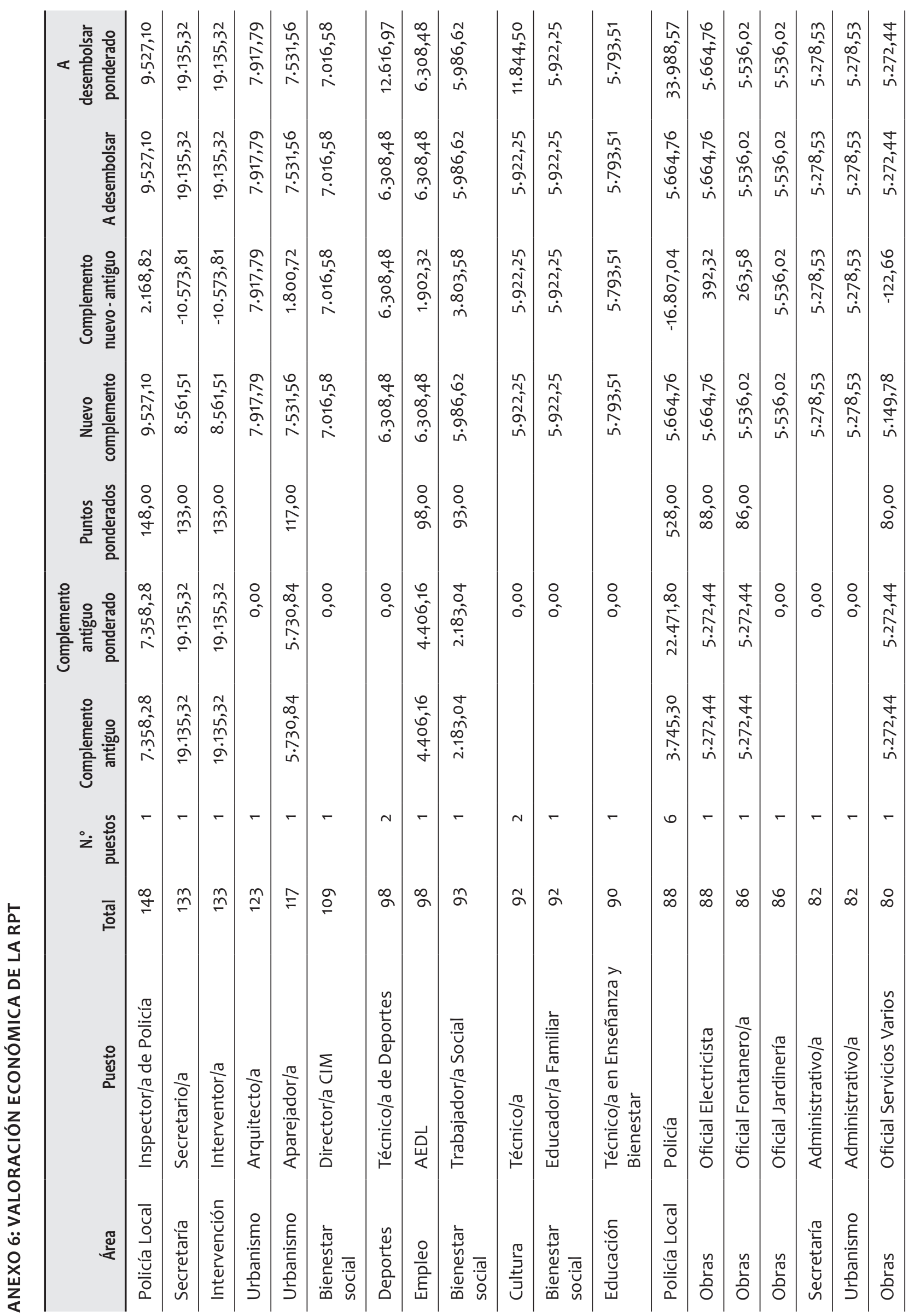




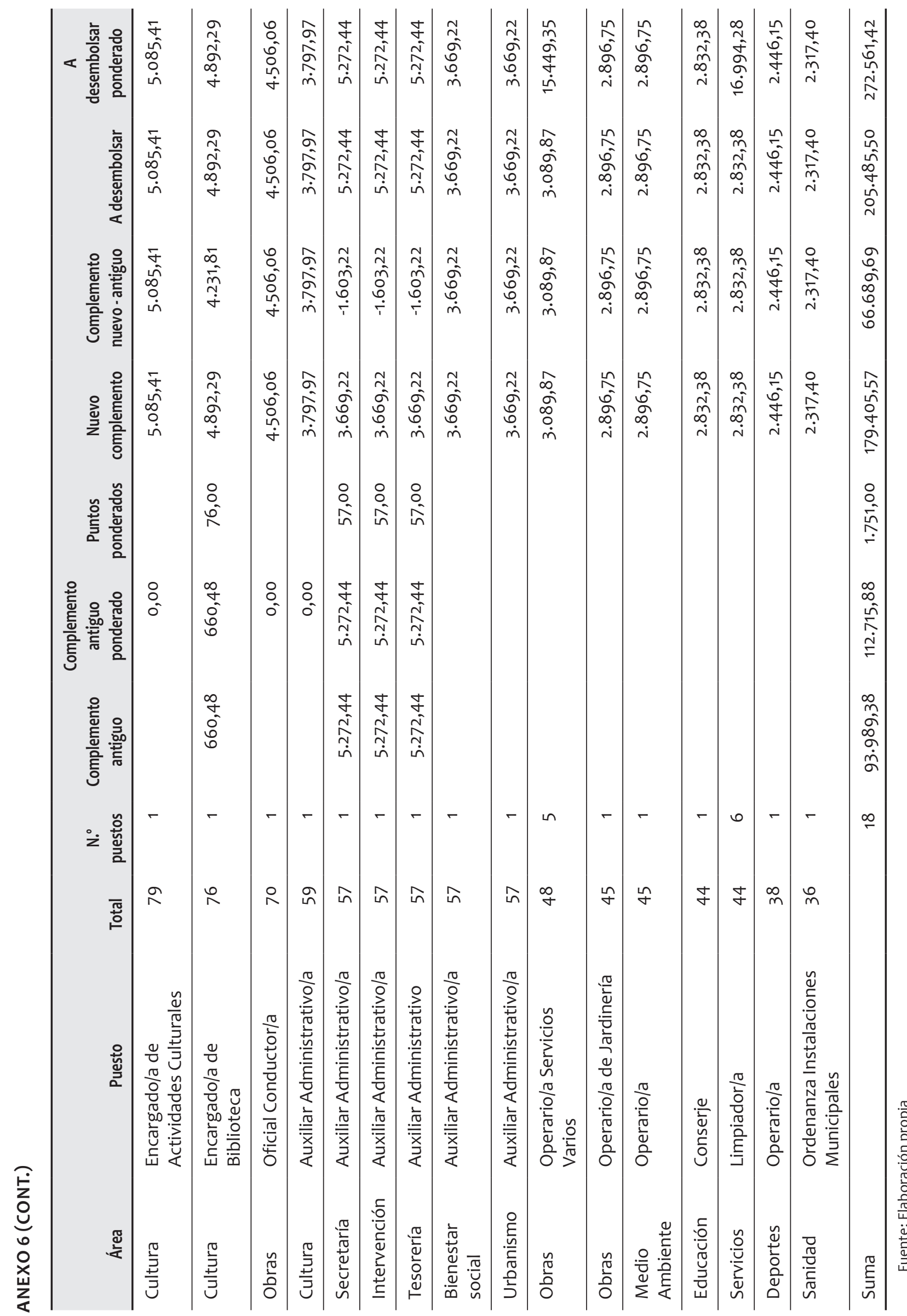

